Jaime Andrés Benavides Gordo*, William Orlando Toro Rodríguez**, Laura López Estupiñán***

\title{
El reconocimiento pedagógico del patrimonio arqueológico: caso Turmequé, Boyacá ${ }^{1}$
}

The pedagogical recognition of archaeological heritage: case Turmequé, Boyacá.

\section{Cómo citar:}

Benavides Gordo, J., Toro Rodríguez, W. \& López Estupiñán, L., 2021. El reconocimiento pedagógico del patrimonio arqueológico: caso Turmequé, Boyacá. Designia, 8(2), 93-111.

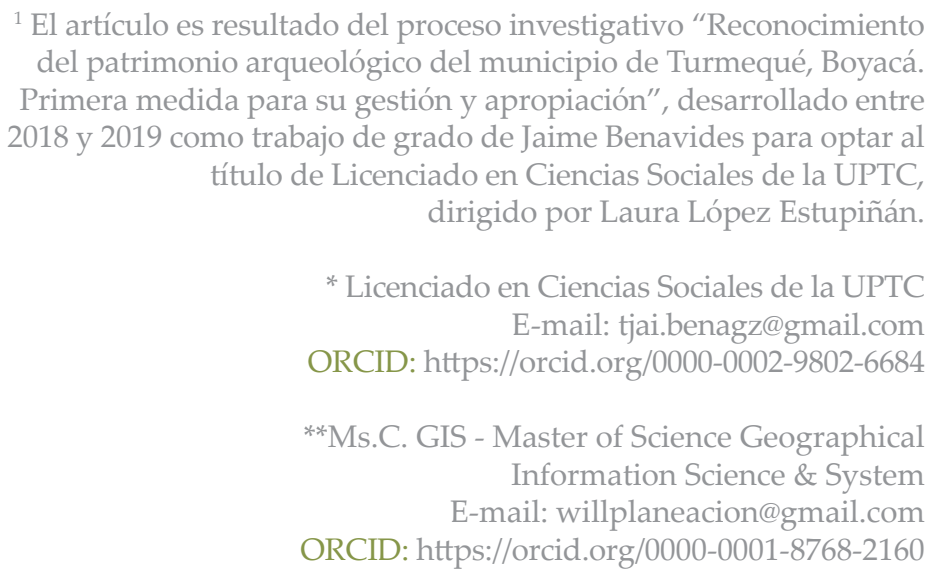

***Ms.C. Arqueología sudamericana (UNT) y Modelización (Rennes1). CReAAH - Centre de Recherche en Archéologie, Archéosciences, Histoire. Docente Escuela de Ciencias Sociales de la UPTC. E-mail: laloes2@gmail.com ORCID: https://orcid.org/0000-0002-9923-3984
Palabras clave:

Patrimonio cultural, educación comunitaria, reconocimiento arqueológico

Key words:

Cultural heritage, community education, archaeological survey

Recibido: 05/05/2020

Aceptado: 25/08/2020 


\section{Resumen:}

Definir los potenciales arqueológicos de los municipios en Colombia es una tarea difícil por la desinformación, los altos costos que genera y los temores de propietarios de predios a la hora de denunciar y registrar un sitio arqueológico. Sin embargo, existen alternativas metodológicas participativas y pedagógicas que permiten el reconocimiento y la gestión socioeducativa del patrimonio arqueológico, los cuales recurren a ejercicios interdisciplinares que vinculan actores sociales y garantizan la apropiación del patrimonio. Para el caso de Turmequé, se reconocieron cinco actores sociales claves en la protección y salvaguarda de bienes, quienes a su vez permitieron la identificación de 56 bienes muebles, 28 bienes inmuebles y 7 sitios con arte rupestre, consolidando un primer inventario y una zonificación arqueológica del municipio que permita definir los lineamientos para su gestión y conservación desde la articulación institucional, tal y como se evidencia en este artículo de investigación.

\section{Abstract:}

Defining the archaeological potentials of the municipalities in Colombia is a difficult task due to the misinformation, the high costs it generates and the fears of property owners when it comes to reporting and registering an archaeological site. However, there are participatory and pedagogical methodological alternatives that allow the recognition and socio-educational management of archaeological heritage, which resort to interdisciplinary exercises that link social actors and guarantee the appropriation of heritage. In the case of Turmeque, five key social actors in the protection and safeguarding of property were recognized, who in turn allowed the identification of 56 movable property, 28 real estate and 7 sites with rock art, consolidating a first inventory and an archaeological zoning of the municipality that allows defining the guidelines for its management and conservation from the institutional articulation, as evidenced in this research article. 


\section{INTRODUCCIÓN}

El patrimonio arqueológico colombiano comprende las huellas y vestigios de las poblaciones prehispánicas, coloniales, republicanas y recientes (Museo del Oro. Banco de la República, 2012). Está conformado por bienes muebles e inmuebles, de carácter inembargable, imprescriptible e inalienable, es decir que su comercialización está prohibida y su tenencia es regulada por la Ley 1185 de 2008 (Artículo 3) y el Código de Policía (Artículo 112 de la Ley 1801 de 2016). Sin embargo, previo a la Ley de Cultura de 1997 y la Constitución Política de 1991, los manejos del patrimonio afectaron gran parte de los sitios arqueológicos con intervenciones de guaquería que terminaron con la destrucción de los bienes. Pese a los cientos de intervenciones en los sitios arqueológicos, aún es posible encontrar bienes muebles en manos de familias custodias que, de manera voluntaria, han asumido la conservación de los sitios y de los bienes, haciendo urgente un proceso de educación patrimonial que permita adelantar procesos de inventario, registro y tenencia según los lineamientos del Instituto Colombiano de Antropología e Historia -ICANH.

Este es el caso de Turmequé, municipio del altiplano Cundiboyacense, reconocido históricamente por su gran riqueza cultural y la presencia de bienes arqueológicos, fomentando el estudio de nuevos escenarios para el cuidado y salvaguarda del patrimonio arqueológico. Con las iniciativas en la tenencia de piezas, investigaciones previas, registros en el sistema nacional de Geoparques (ICANH) y revisión de colecciones nacionales, se consolidó un primer inventario arqueológico de bienes muebles e inmuebles para Turmequé. Para ello, fue necesaria la revisión histórica, etnohistórica y documental del municipio, permitiendo recabar información en torno a los bienes muebles e inmuebles arqueológicos, sus zonas y áreas de concentración, su estado de conservación y las dinámicas culturales que se tejen en torno a estos lugares. 
Durante el proceso, fue evidente la desconfianza y resistencia por parte de las comunidades, por lo que, en una segunda etapa, fue necesario un reconocimiento participativo, incluyente de una metodología pedagógica amparada en la comunión de actores sociales (agentes comunitarios, tenedores, familias custodias, administración municipal e instituciones educativas) y 6 elementos para lograr el reconocimiento pedagógico (recorrer, identificar, delimitar, caracterizar precisar y documentar). A partir de una estrategia de diálogo, se logró el reconocimiento y la documentación de 56 bienes muebles, 28 bienes inmuebles y 7 sitios con arte rupestre, generando una propuesta de zonificación arqueológica del municipio.

El mecanismo que guió el trabajo de campo fue el diálogo de saberes, escenario donde se aprende mutuamente, se construyen nuevos conocimientos y realidades en torno al patrimonio, consolidando procesos de reconocimiento y aprovechamiento responsable de los bienes y sitios arqueológicos, permitiendo comprender los diversos usos culturales del territorio y nominando coordenadas geográficas. El trabajo de campo permitió documentar la valoración cultural de los bienes, sus tensiones, experiencias y desafíos, producto de las malas experiencias de procesos anteriores, donde las personas terminaron siendo engañadas y/o los bienes arqueológicos terminaron con serias afectaciones o vendidos.

El preocupante estado de conservación de algunos bienes inmuebles motivó la implementación de una estrategia divulgativa que garantizará la gestión y apropiación de los bienes, profundizando en acciones de conservación preventiva de los mismos. La estrategia está enfocada en iniciativas culturales responsables que giran en torno al patrimonio arqueológico, tales como propuestas museológicas, caminatas, talleres, murales, comunicación en redes sociales y proyectos transversales entre la administración municipal, el sector educativo, bibliotecas y organizaciones comunales, dando al municipio la oportunidad de realizar un proceso de apropiación que garantice la conservación de los bienes arqueológicos. 
El artículo 189 de la Constitución Política de Colombia de 1991 y el numeral 2.6.2.14 del Decreto 1080 del 2018 que modifica la Ley 1185 de 2008, refieren al registro de bienes que integran el patrimonio arqueológico, el cual es competencia del ICANH y tiene propósitos de inventario, catalogación e información cultural. Para el caso Boyacense, los bienes inmuebles más comunes son soportes rocosos con arte rupestre (petroglifos, pictografías y moyas), que han sido registrados en los municipios de Buenavista, Ciénega, Chita, Corrales, Combita, Cuítiva, Duitama, Gámeza, Güicán, Iza, Motavita, Mongua, Monguí, Pesca, Ramiriquí, Rondón, Sáchica, Santa Rosa, Socha, Sogamoso, Tasco, Tipacoque, Toca, Tópaga, Turmequé, Tutazá, Villa de Leyva y Ventaquemada.

Sus estudios comprenden inventarios y documentaciones (Argüello y Martínez, 2003; Becerra, 1986; Benavides, 2020; Flórez, 1998; GIPRI y Fundación Piedra Alta, 2015; GIIAH, 2012a, 2012b, 2012c, 2012d; Pérez, 2013; Pérez de Barradas, 1941; Pradilla, 2010; Triana, 1972; Trujillo, 2002), técnicas de elaboración (Bateman y Martínez, 2001), estudios de localización (Cepeda, 2016; Guerrero 2018), documentación de narrativas y procesos de apropiación (Hurtado, 2015; Fundación cultural Benítez, 2016; López, 2011, 2018). Argüello plantea que, "paralelamente a los procesos de documentación del arte rupestre, se ha advertido la forma recurrente como este objeto ha sido intervenido y cómo tales intervenciones han derivado en su deterioro o incluso destrucción" (2018: 53).

Ante la situación, común al departamento de Boyacá, se ratifica la urgencia de reconocimientos pedagógicos que permitan documentar los bienes, sitios y condiciones de conservación con el fin de delimitar áreas arqueológicas, generar zonificaciones y procesos de gestión socioeducativa que regulen la expansión urbana e industrial, minimicen las afectaciones antrópicas (vandalismo y guaquería) y garanticen la apropiación social de los sitios. El registro de bienes ha sido liderado por investigadores arqueólogos, sin embargo, muy pocos custodios han registrado los bienes muebles y recibido la tenencia de las piezas.

El artículo 3 de la Ley 1185 de 2008 y artículo 12 de la Ley 1801 de 2016 reconocen a particulares y privados como tenedores de piezas, quienes deben adelantar el proceso ante el ICANH. Pese a las facilidades del registro en línea, los custodios enfrentan temores y angustias basadas en la desinformación, situación que hace urgente emprender acciones pedagógicas que permitan informar, asesorar y acompañar los procesos de registro en los municipios. Ante el panorama, el Museo Arqueo- 
lógico de Tunja -Uptc, propuso, entre 2017 y 2019, el reconocimiento pedagógico en la consolidación de inventarios arqueológicos mediante el acompañamiento a las iniciativas educativas de los semilleros de investigación Furachogua (Institución Técnica Educativa San Pedro de Iguaque), Huellas Tutaceñas (Escuela la Victoria de Tutazá) y el municipio de Tipacoque, logrando el registro de las colecciones por parte de las administraciones municipales ante el ICANH (López y otros, 2019).

El reconocimiento pedagógico de los bienes arqueológicos se fundamenta en el trabajo reflexivo con los actores sociales de los territorios, no sólo para llegar a los sitios, o para emplearlos como auxiliares, sino para involucrarlos en el proceso pedagógico de enseñanza-aprendizaje que éste implica. El proceso recurre al modelo de educación patrimonial centrado en el discente, el contenido y el contexto, el cual acoge diversas estrategias de enseñanza aprendizaje que respondan a las necesidades y contextos locales (Fontal y Marín, 2011). Diálogos de saberes, encuentros intergeneracionales, recorridos territoriales, acompañamientos en las labores tradicionales, acuerdos y adecuación de casas como laboratorios de conservación preventiva de bienes muebles fueron algunas de las estrategias empleadas para garantizar el acceso, la identificación, valoración, registro y apropiación social de los bienes.

Lejos de contar con un Plan Nacional de Educación Patrimonial como ocurre en países de Europa, en Colombia se hacen urgentes procesos educativos y currículares vinculantes de acciones pedagógicas de transferencia, mediación cultural y comunicación entre actores sociales que garanticen la construcción social del patrimonio (Canclini, 2007; Montenegro, 2012; Zabala y Roura, 2006). Martínez (2015) reconoce los tenedores (museos, instituciones y particulares), comunidades, comerciantes ilícitos, guaqueros y arqueólogos como actores relacionados con los bienes muebles; mientras que, los propietarios del predio (particular, Estado) y las comunidades están relacionados con los bienes inmuebles; siendo evidente la presencia de las comunidades en el reconocimiento del patrimonio arqueológico mueble e inmueble.

Martínez recurre al concepto de comunidad del Ministerio de Cultura (2005), como "la agrupación de personas que se interrelacionan en un territorio y tiempo determinados y/o alrededor de un interés común" (Martínez, 2015: 62), sin embargo, es necesario reconocer que el patrimonio arqueológico en Colombia ha sido un tema polémico que ha generado desconfianzas, temores, desaciertos e incomodidades en las comunidades donde se han notificado hallazgos fortuitos. El desconocimiento de la ley, los supuestos derechos sobre las propiedades, los usos de las comunidades por parte de los investigadores, la desinformación y la falta de seguimiento a las afectaciones del patrimonio, han disuelto el concepto de comunidad en el patrimonio cultural, capitalizando las interpretaciones y memorias en fundaciones, organizaciones y particulares. 
La problemática expuesta evidencia la necesaria y urgente común unidad en los intereses y objetivos en la apropiación social y la gestión del patrimonio por parte de los actores sociales: la protección y salvaguarda del patrimonio. En esta perspectiva, es necesario destacar las iniciativas educativas de docentes y estudiantes, quienes han realizado inventarios pedagógicos de bienes y sitios arqueológicos en Buenavista, Iguaque, Motavita, Tutazá y Tipacoque, los cuales fueron articulados al proceso educativo como eje transversal en la enseñanza de diversas áreas, principalmente ética, artística y ciencias sociales.

Con las experiencias de Boyacá, y teniendo en cuenta las particularidades históricas del municipio de Turmequé, se planteó un inventario pedagógico que reconociera los actores sociales vinculados con el cuidado y salvaguarda del patrimonio arqueológico del municipio: agentes (líderes comunales, vigías del patrimonio, conocedores de la temática e interesados en el patrimonio arqueológico), tenedores (actores reconocidos institucionalmente: museos), familias custodias (familias que han cuidado y salvaguardado bienes muebles encontrados dentro de sus predios por hallazgos fortuitos desde hace más de dos generaciones), administración municipal, instituciones educativas y artesanos.

Los agentes, tenedores y familias custodias fueron eje fundamental del reconocimiento arqueológico, su conocimiento dinamizó un ejercicio de memoria que permitió identificar los lugares exactos donde se hicieron los hallazgos fortuitos y donde están ubicados los SAR. Con los agentes se confirmó y descartó la existencia del bien, se nombraron los sitios que aparecían como indeterminados en registros anteriores, se documentaron los relatos y se logró la zonificación de las áreas con potencial arqueológico. Sin ninguna duda, los relatos corresponden a una tradición oral que permite comprender la permanencia de un patrimonio vivo, apropiado, valorado y salvaguardado en Turmequé, por lo cual se propuso la implementación de diálogos de saberes en la cocina, en el surco, en la portada y el camino. 
Recorrer, identificar, delimitar, caracterizar, precisar y documentar fueron los 6 pasos necesarios para lograr el reconocimiento pedagógico del patrimonio arqueológico junto a los agentes comunitarios, tenedores de piezas y familias custodias. El recorrer implicó ir a la zona, caminar, observar el paisaje, participar de las dinámicas sociales de las comunidades que habitan ese territorio y ubicar los sitios arqueológicos. En el sitio, se identificó el carácter arqueológico del bien, se localizó geográficamente en un proceso de cartografía social y finalmente se delimitó el sitio mediante la nominación del lugar y la determinación de los bienes encontrados (mueble o inmueble).

Luego, se realizó la caracterización, es decir, se definió la tipología, usos, posibles funciones y contextos de los bienes arqueológicos, permitiendo precisar las relaciones de los bienes con el paisaje y el contexto arqueológico en el que se encuentran, facilitando la zonificación de áreas con potencial. Como resultado, se consolidó una ficha que permitió registrar los datos relacionados con bienes muebles e inmuebles y se documentó cada bien mediante el registro fotográfico, la recolección de relatos, vivencias y conflictos, datos de las piezas, estados de conservación y anotaciones a los sitios arqueológicos. La caracterización y documentación fue la base del proceso de registro y tenencia ante el ICANH.

El proceso descrito responde al modelo de educación patrimonial de Fontal y Marín (2011), respondiendo a las dinámicas del saber-hacer, práctica muy común en las poblaciones campesinas de Boyacá. Cualquier lugar fue el indicado para evidenciar la importancia del patrimonio arqueológico, esos "objetos y piedras pintadas" que representan la identidad campesina y la historia del municipio. Los hogares de los actores sociales fueron los laboratorios fotográficos que permitieron, a su vez, el diagnóstico de conservación de las piezas in situ, el permiso y acceso a los predios y la reflexión en torno al registro y tenencia de las piezas por parte de las familias custodias. Se realizó acompañamiento en labores de conservación preventiva en líticos y cerámica, mediante soportes en jumbolon y fique que aislarán las superficies y evitarán daños en la decoración y/o marcas de uso.

Durante ocho meses de trabajo de campo en 13 veredas y el área urbana de Turmequé, se realizó el reconocimiento pedagógico, identificando 56 bienes muebles (22 bienes en cerámica y 34 líticos) y 28 bienes inmuebles, principalmente soportes rocosos con arte rupestre (18 con pictografías, 9 con moyas y 1 con petroglifos). Con los bienes y sitios identificados, la tradición oral, los hallazgos fortuitos y la relación paisajística de los bienes con los sitios (sin intervención al suelo, ni a los bienes), se generó una primera propuesta de zonificación arqueológica. 


\section{Zonificación y análisis espacial de los sitios arqueológicos en Turmequé.}

Las zonificaciones tradicionales han sido realizadas mediante reconocimientos intensivos, prospecciones arqueológicas y/o geofísicas. Sin embargo, el reconocimiento pedagógico, incluyente de la tradición oral, no había sido utilizado en las zonificaciones arqueológicas. De ahí que esta propuesta sea innovadora, permitiendo disminuir los costos en el reconocimiento, generar un proceso comunitario y participativo constante que garantice la apropiación social del patrimonio arqueológico.

El método corresponde a un proceso experimental que permitió el reconocimiento de actores sociales, la sistematización y registro de los bienes, la enseñanzaaprendizaje en labores de conservación preventiva y minimización de acciones que afectarán los bienes mediante técnicas no invasivas como prospección superficial, fotografía, el reconocimiento territorial, la generación de soportes para los bienes muebles y las campañas educativas que involucran el trabajo intersectorial. Como resultado se obtuvo una primera cartografía social que permitió ubicar todos los sitios documentados durante la revisión bibliográfica y el reconocimiento pedagógico en google earth, permitiendo la zonificación de 7 SAR (Benavides, 2020: 101), dos tipos de zonas arqueológicas (por su potencial alto y medio-bajo) y una zona relacionada con imaginarios culturales y arqueológicos en sitios naturales (Benavides, 2020: 101).

La zona con alto potencial arqueológico y los datos reportados en el sistema de Geoparques (ICANH) fueron geolocalizados en ArcGIS y superpuestos con la cartografía actualizada al 2016 en el IGAC, con el fin de realizar un análisis espacial en el que básicamente se vincula un modelo de conectividad estructural espacial, es decir, se analiza la cercanía espacial o distancias euclidianas entre eventos geográficos, de manera que permita reconocer las aglomeraciones que se presentan con cada uno de los bienes arqueológicos registrados. Para ello, se utilizó el método de interpolación geo estadístico conocido como Kriging, el cual está constituido bajo un modelo estadístico que incluye la auto correlación de datos absolutos o coordenadas exactas con una ubicación geográfica. Para este caso se utilizaron datos con proyección de información cartográfica correspondiente al Datum WGS84, homologable al proyecto SIRGAS para Colombia, que ofrece relaciones estadísticas entre los puntos medidos. 
Con la evaluación de la información, las técnicas de estadística geográfica no solo tienen la capacidad de producir una superficie de predicción, en este caso de aglomeración, sino que también proporcionan alguna medida de certeza o precisión de las predicciones geo espaciales puntuales. El método Kriging pondera los valores medidos circundantes para calcular una predicción de una ubicación incluso sin mediciones (localización relativa). La fórmula general para ambos interpoladores se forma como una suma ponderada de los datos representada de la siguiente manera:

$$
Z\left(S_{o}\right)=\sum_{i=1}^{N} \lambda_{i} Z\left(S_{i}\right)
$$

Donde:

$\mathrm{Z}\left(\mathrm{s} \_\mathrm{i}\right)$ = el valor medido en la ubicación n.i

$\lambda \_\mathrm{i}=$ un peso desconocido para el valor medido en la ubicación n. $\mathrm{o} i$

s_0 = la ubicación de la predicción

$\mathrm{N}=$ el número de valores medidos

Con el método Kriging, la correlación espacial debe estar cuantificada (Oliver, M.A. 1990), las ponderaciones están basadas no sólo en la distancia entre los puntos medidos y la ubicación de la predicción, sino también en la disposición espacial general de dichos puntos. Por tanto, en kriging ordinario, el peso, $\lambda \_i$, depende de un modelo ajustado a los puntos medidos, la distancia a la ubicación de la predicción y las relaciones espaciales entre los valores medidos alrededor de la ubicación de la predicción. 
A partir de este análisis es posible evaluar las densidades superponiendo la conformación geo administrativa que tiene el municipio de Turmequé y en el que es posible evidenciar un mayor número de eventos arqueológicos en la vereda Rosales, seguido de las veredas Rinchoque, Pozo Negro y Jurata (Figura 1). Para este caso particular, los sistemas de información geográfica, específicamente el uso de herramientas geo estadísticas, brinda la posibilidad de obtener resultados que apoyan la gestión territorial en una temática arqueológica y comprender si existían patrones o correspondencias entre las distribuciones espaciales relacionadas con ciertas características del entorno espacial.

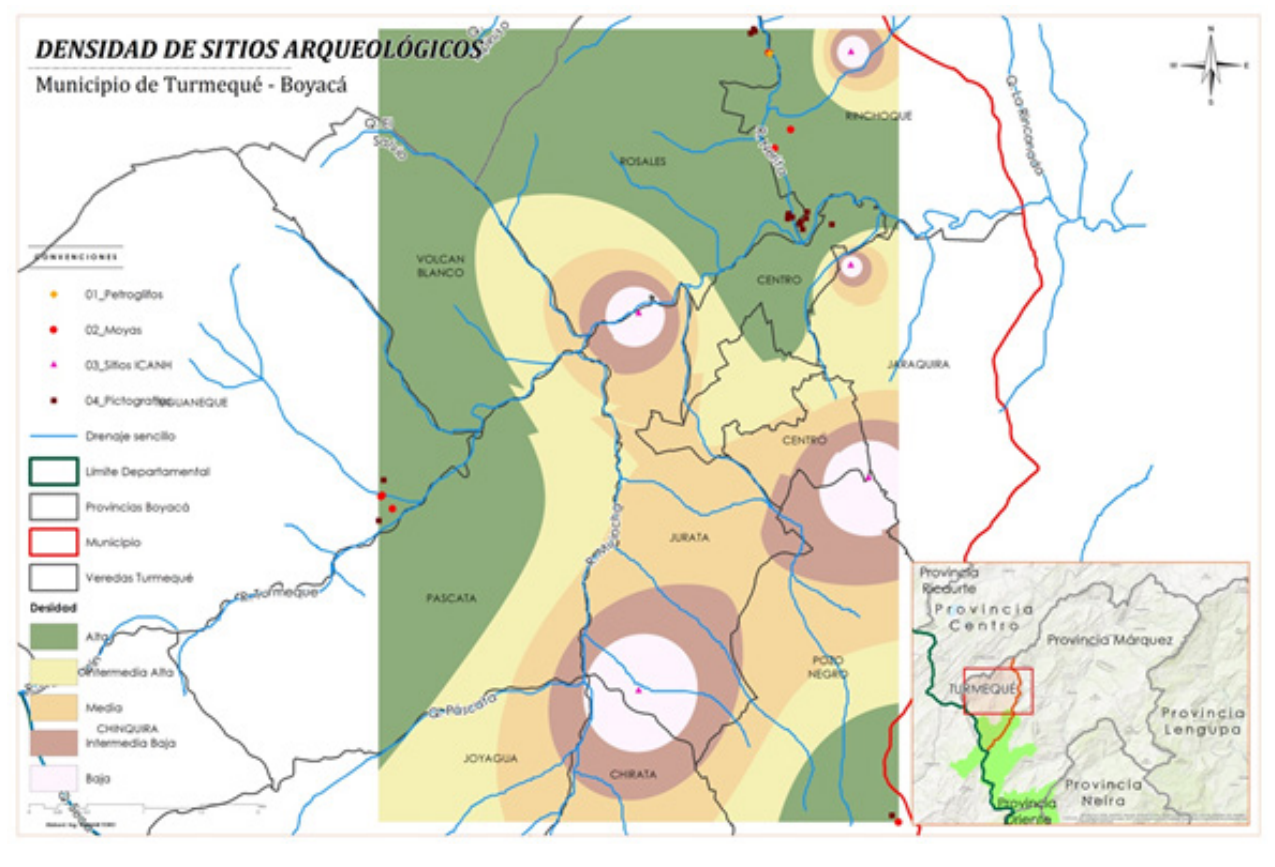

Figura 1. Densidad de sitios arqueológicos del municipio de Turmequé al 2019. Fuente: Elaboró William Toro Rodríguez. Información base recolectada por Jaime Benavides, Geoparques (ICANH), IGAC 2016. 
La presencia de 28 soportes rocosos con evidencias de arte rupestre confirma la existencia de 28 bienes inmuebles agrupados en espacios particulares que comprenden parte media de los cerros y valles de las riberas. Aunque el análisis espacial permite definir 3 SAR (uno al nororiente, otro al occidente y otro al sur del municipio), los pobladores reconocieron $7 \mathrm{SAR}$ por las dinámicas socioculturales, toponímicas y paisajísticas (Figura 2). Los 18 soportes rocosos con pictografías se encuentran en seis de los siete SAR reconocidos culturalmente, exceptuando el SAR La Magdalena, lugar donde se encuentran dos soportes rocosos con la mayor cantidad de moyas. El único soporte rocoso con petroglifos reconocido hasta el momento se encuentra en el SAR El Genil.

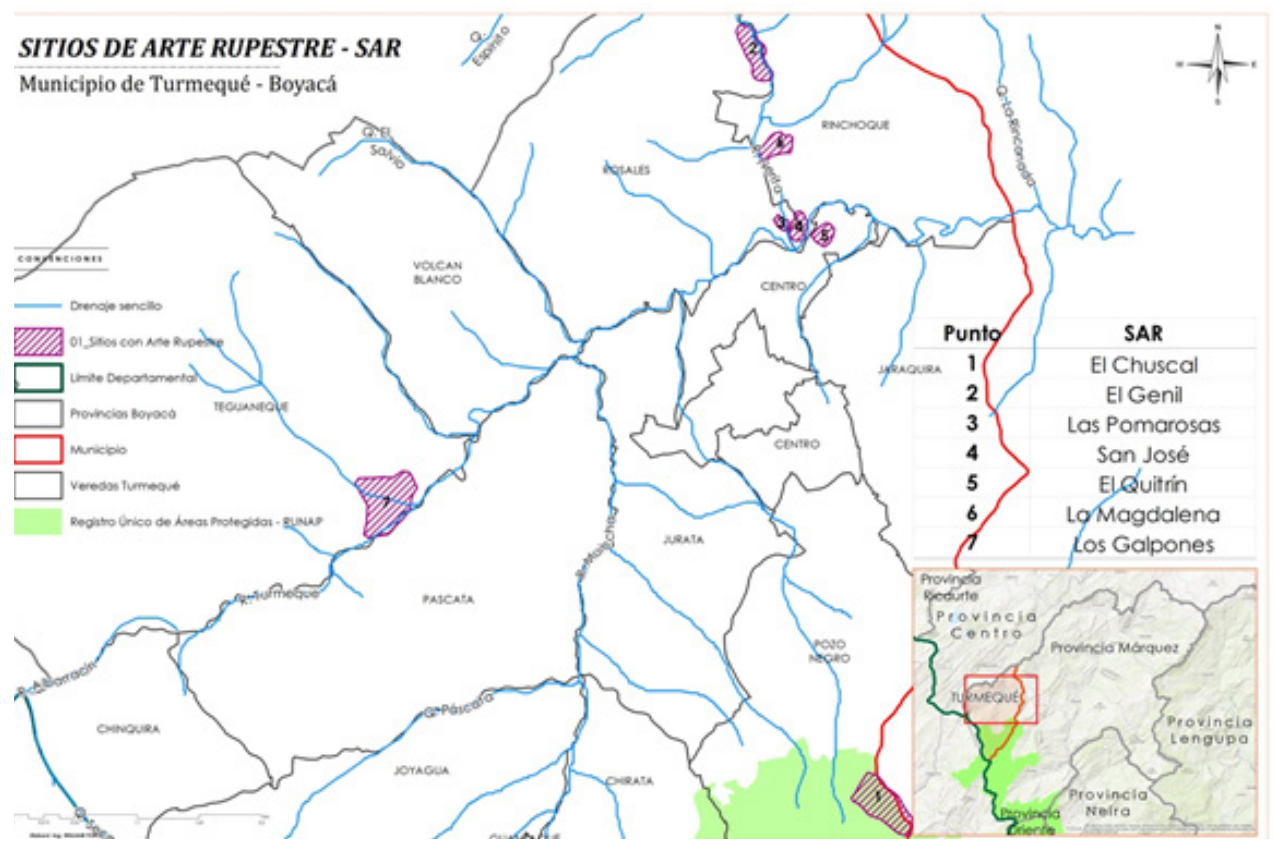

Figura 2. Sitios con Arte Rupestre de Turmequé. Fuente: Elaboró William Toro Rodríguez. Información base recolectada por Jaime Benavides, Geoparques (ICANH), IGAC 2016. 
Hacía una gestión socio educativa del patrimonio arqueológico.

Durante el proceso de reconocimiento del patrimonio arqueológico en Turmequé, se documentó el grave panorama de afectación a los bienes y su contexto (el paisaje), debido al desinterés y nulo control administrativo, el vandalismo, las tensiones sociales y el desconocimiento parcial de los sitios. Los procesos sistemáticos de guaquería y el aprovechamiento irresponsable de los SAR han generado conflictos y afectaciones a los soportes rocosos. Ante la situación, se acordaron compromisos interinstitucionales y estrategias didácticas con el fin de disminuir las afectaciones al patrimonio arqueológico, con el fin de generar impactos positivos en la conservación de los vestigios, mejorando su gestión u apropiación, facilitando el acceso, la información y la creación de lineamientos para su protección.

Para el caso colombiano, Martínez (2015) retoma los ejes de investigación, conservación, divulgación, administración y protección normativa de los Planes de Manejo Arqueológico - PMA-, como ejes de los lineamientos para la gestión patrimonial de SAR, sin embargo, desconoce el papel de la gestión socioeducativa, entendida como un proceso de formación y dinamización de la apropiación social (Fontal 2004). Desde los años 80s, en América Latina, la arqueología comunitaria ha reconocido las comunidades como agentes activos en la investigación, conservación y divulgación del patrimonio arqueológico (Menezes, 2010) y desde los años 90s se han documentado experiencias significativas en Argentina (Albeck, 1996; Podgorny, 1994; Montenegro, 2012), Bolivia (Fernández, 2003) y Colombia (López y otros, 2019; Benavides, 2020), que vinculan la educación en los procesos de construcción social del patrimonio arqueológico.

Para ello, los investigadores han recurrido a la articulación de la arqueología en los contenidos educativos de la educación formal, principalmente a nivel curricular. Sin embargo, en la educación comunitaria se han hecho aportes al diseño de estrategias pedagógicas para acercar los contenidos arqueológicos y patrimoniales a las comunidades desde una mirada intercultural, mediante didácticas varias que reconocen espacios multivocales en talleres y exposiciones que replantean la función del museo (Montenegro, 2012).

Como resultado de los procesos encontramos el reconocimiento del patrimonio arqueológico y sus marcos normativos, la ampliación en numero de inventario, tenencias de colecciones de bienes muebles, registro de sitios arqueológicos con bienes inmuebles, el restablecimiento de la confianza en las comunidades con el sector institucional, la conservación a largo plazo de los bienes y la participación comunitaria en los procesos de divulgación con propuestas de desarrollo auto-sostenible, tales como museos comunitarios. 
Para Londoño, Therrien y Garzón, “el museo es una herramienta pedagógica que busca invitar a la reflexión, la crítica y el análisis de los significados dados a los objetos del pasado, y dentro del cual se incluye la versión de los arqueólogos, pero también la que construyen los distintos públicos" (2001: 74). Como herramienta pedagógica, el museo no es la única en el proceso educativo, los escenarios cotidianos, los sitios de hallazgos fortuitos, las casas de las familias custodias y los sitios que hacen parte del imaginario local son iguales de importantes en el proceso de gestión socioeducativa del patrimonio arqueológico. De ahí la necesidad de comprender las acciones instintivas de las familias custodias en la conservación de los bienes y comenzar un diálogo práctico que muestre las condiciones garantes de la conservación a largo plazo de los bienes muebles e inmuebles, así como las narrativas que evidencian los sentidos, sentires y significados de ese patrimonio que han decidido salvaguardar.

Si bien, se hace necesario reconocer la importancia de los registros y tenencias según el marco legal, estamos seguros de que solo después del reconocimiento pedagógico y de iniciativas colectivas que garanticen un escenario común en la conservación y divulgación de los bienes inmuebles, las comunidades estarán dispuestas a consolidar el proceso de registro y tenencia, tal como ocurrió en Tipacoque durante 2018. Los resultados de estas experiencias han permitido evidenciar el empoderamiento de las comunidades locales y, por ende, el fortalecimiento del proceso de apropiación social del patrimonio arqueológico; razón por la cual se reconoce la gestión socioeducativa como garante del éxito en los procesos de apropiación social.

Las investigaciones realizadas desde la educación patrimonial y la arqueología pública evidencian que el patrimonio arqueológico es un elemento didáctico en la enseñanza - aprendizaje de las diversas ciencias (sociales, artes, física, matemática, ética, geografía, historia, naturales...), "permite comprender los discursos de poder y las distintas realidades, contrastar las políticas gubernamentales, combatir el etnocentrismo, mantener y reafirmar la identidad cultural" (Canclini, 2007; Londoño, Therrien y Garzón, 2001: 75).

El proceso educativo convierte a la didáctica en un mecanismo de apropiación social y educativa del patrimonio arqueológico puesto que permite dinamizar los procesos educativos, sus materiales y relaciones. Su iconografía, contexto y paisaje pueden motivar la creación de materiales didácticos que den respuesta a las exigencias 
locales, vinculándose en proyectos de aula y proyectos transversales exigidos por el Ministerio de Educación Nacional, propuestas y estrategias en el fomento de la lectoescritura de la Red Nacional de Bibliotecas u herramientas para el fortalecimiento de la identidad cultural en casas de la cultura, tales como la inclusión del patrimonio arqueológico en las tradiciones campesinas y aguinaldos.

Este proceso implica la articulación de actores sociales (familias custodias, agentes comunitarios, tenedores, institucionales y educativos), proyectos educativos, tradiciones, costumbres campesinas, trabajos artesanales, potenciales artísticos y medios de comunicación que garanticen la divulgación de experiencias y características del patrimonio arqueológico. El uso de las tic's y redes sociales, como medios que permiten visibilizar y comunicar a nivel regional y global, es indispensable en el proceso. La interconexión del mundo contemporáneo permite llegar a otros actores sociales y nutrir los procesos de reconocimiento patrimonial, además de generar un proceso educativo que concientice a los ciudadanos en el manejo, protección y cuidado del patrimonio arqueológico.

Con un trabajo divulgativo paralelo que permita los diálogos entre actores, medios y herramientas a nivel local y global, es posible la puesta en marcha de acuerdos políticos que visibilicen el patrimonio arqueológico en los Planes de Desarrollo y Esquemas o Planes de Ordenamiento Territorial (Ley 1185 de 2008), garantizando así la ejecución de proyectos y PMA que incluyan la gestión socioeducativa de los sitios y bienes. De lo contrario, los municipios e interesados seguirán pagando la formulación de PMA que no responden a las necesidades locales y regionales, que desconocen las dinámicas socioculturales de las poblaciones y aceleran los procesos de destrucción o abandono de los sitios arqueológicos.

Con las experiencias en la formulación y ejecución de los planes de manejo sabemos que, solo mediante la gestión socio educativa del patrimonio se logra: a) Minimizar las afectaciones biológicas, b). Visibilizar la importancia cultural de los sitios, c). Garantizar su apropiación social y, por ende, su conservación a largo plazo.

\section{CONCLUSIONES}

El reconocimiento pedagógico se convierte en un método participativo incluyente del recorrer, identificar, delimitar, caracterizar, precisar y documentar los bienes y contextos arqueológicos. Su aplicación en el municipio de Turmequé permitió identificar 56 bienes muebles, 28 bienes inmuebles, 7 SAR, una zonificación arqueológica y un valioso proceso que reivindicó los diálogos intergeneracionales, los acuerdos con actores sociales y el registro de bienes insitu. 
El método recurre al uso de técnicas no intrusivas como los sistemas de información geográfica, la didáctica y la tradición oral, aliados en la identificación, registro, documentación y análisis de los bienes. El resultado del análisis espacial permite proponer y dar respuesta a un interrogante a nivel geográfico: ¿En dónde se encuentran las principales correspondencias entre las distribuciones espaciales relacionadas con ciertas características del entorno espacial?. Para lo cual, es evidente una relación entre las zonas con alto potencial arqueológico, el recorrido del río Nerita, las zonas intermedias de los cerros, confirmando las descripciones etnohistóricas (Simón, 1981; Triana, 1972) que mencionan los cerros y ríos como santuarios y/o sitios rituales de los Muiscas.

Los pobladores de Turmequé reconocen un vinculo entre los SAR y el agua (ríos, quebradas, nacederos, manas de agua o aljibes naturales), las formaciones geológicas (cerros y cuevas) y los sitios sagrados o rituales de los antiguos. Algunos de ellos están asociados a sitios de ocupación y vivienda en tiempos prehispánicos, funcionan como límites, señales del camino (al estar cerca de los caminos antiguos o reales) y están relacionados con la mitología en relatos orales. Sus motivos pueden coincidir gráficamente con otros encontrados en la decoración de la cerámica.

La confianza, el respeto y el reconocimiento de custodios y tenedores como principales actores sociales en el cuidado, protección y salvaguarda del patrimonio arqueológico permitieron la articulación de actores institucionales, educativos y sociales en la creación de acuerdos y compromisos que garantizan, a largo plazo y de manera sostenible, la gestión socio-educativa y, por ende, la apropiación social del patrimonio arqueológico en Turmequé.

El reconocimiento pedagógico es una alternativa al reconocimiento del patrimonio arqueológico, las experiencias de licenciados en ciencias sociales y voluntarios del Museo Arqueológico de Tunja entre 2016 y 2019 permitieron evidenciar un campo de acción necesario para garantizar la apropiación y divulgación del patrimonio. El trabajo interdisciplinar ya comienza a tener frutos, los docentes comenzaron a vincular el patrimonio cultural y arqueológico como parte de los lineamientos curriculares, los derechos básicos de aprendizaje y el quehacer institucional. Hoy el municipio de Turmequé vincula la investigación como referente y dinamiza proyectos que dan continuidad al proceso iniciado en 2019. Se espera que como Turmequé, los demás municipios puedan replicar este modelo metodológico en el reconocimiento de sus patrimonios. 


\section{REFERENCIAS BIBLIOGRÁFICAS}

Albeck, M., Calvo, M., González, A., Portal, H., y Viste, L. (1996). Quebrada de Humahuaca: Más de 10.000 Años de Historia. Argentina, Escuela Normal Dr. Eduardo Casanova y Universidad Nacional de Jujuy.

Arguello, P. (2018). Capítulo 6. Arte rupestre como patrimonio: un objeto visible “invisibilizado". Arte rupestre en Colombia. Investigación, preservación, patrimonialización, (págs. 153-178). Tunja, Colombia: UPTC.

Arguello, P., y Martínez, D. (2003). Documentación del yacimiento rupestre de Sáchica (Boyacá) Calizas y Agregados Boyacá S.A. Recuperado el 20 de febrero de 2020, de http://www.rupestreweb.info/sachica.html

Bateman, C., y Martínez, A. (2001). Técnica de elaboración de las pictografías ubicadas en el área de curso del río Farfacá. Recuperado el 10 de enero de 2020, de http://rupestreweb.info/farfaca.html

Becerra, V. (1986). Abrigos naturales de la región de Ventaquemada, Puente de Boyacá, utilización prehistórica pintura rupestre, Colombia, FIAN.

Benavides, J. (2020). Reconocimiento del patrimonio arqueológico del municipio de Turmequé, Boyacá. Primera medida para su gestión y apropiación. [Tesis de pregrado], UPTC, Tunja.

Canclini, N. (2007). Arqueología y educación. Estado de la cuestión. Cuicuilco (39), 203-226.

Cepeda, R. (2016). Arte rupestre prehispánico en el valle de Sogamoso: uso restringido o libre. Informe final de la investigación financiada por el programa Fomento a la investigación ICANH, Colombia, ICANH.

Fernández, M. (2003). Comunidades locales y la enseñanza de la arqueología: una experiencia en Bolivia. Chungara Revista de Antropología Chilena (35), 355-359.

Flórez, F. (1998). Informe sobre el hallazgo de vestigios de "un grupo cultural prehispánico a los Muiscas" en inmediaciones del Municipio de Iza (Boyacá). Informe presentado al Instituto Colombiano de Antropología, Colombia, ICANH.

Fontal, O. (2016). Educación patrimonial: retrospectiva y prospectivas para la próxima década. Estudios Pedagógicos (XLII), 415-436.

Fontal, O. (2013). Estirando hasta dar la vuelta al concepto de patrimonio. La educación patrimonial: del patrimonio a las personas, 9-12. Girón, España: Trea.

Fontal, O., y S. Marín. (2011). Enfoques y modelos de educación patrimonial en programas significativos de OEPE. Educación artística revista de investigación (2), 91-96. 
Fontal, O. (2004). La dimensión contemporánea de la cultura. Nuevos planteamientos para el Patrimonio Cultural y su educación. Comunicación educativa del patrimonio: referentes, modelos y ejemplos., (págs. 81-104). Girón, España: Trea.

Fundación cultural Benítez. (2016). Senderos rupestrológicos en tierras del cacique Socha, Tunja, Colombia: Buhos editores.

GIPRI y Fundación Piedra Alta. (2015). Registro y Documentación del Patrimonio Rupestre del Municipio de Sogamoso, Boyacá. Informe Final. Sogamoso, Colombia.

GIIAH - Grupo interdisciplinario de investigaciones arqueológicas e históricas de la UPTC. (2012a). Inventario georreferenciación y valoración del Patrimonio Arqueológico del municipio de Sáchica, Tunja, Colombia: UPTC.

(2012b). Inventario, georreferenciación y valoración del Patrimonio Arqueológico del municipio de Floresta. Tunja, Colombia: UPTC.

(2012c). Inventario, georreferenciación y valoración del Patrimonio Arqueológico del municipio de Ramiriquí. Tunja, Colombia: UPTC.

(2012d). Inventario, georreferenciación y valoración del Patrimonio Arqueológico del municipio de Mongua. Tunja, Colombia: UPTC.

Guerrero, A. (2018). Arte rupestre y diferenciación social: estudio de la localización del arte rupestre y patrones de asentamiento prehispánicos en Tunja y Motavita (Boyacá - Colombia) [Tesis de pregrado], UPTC, Tunja.

Hurtado, N. (2015). Las pictografías de Sáchica desde las narraciones orales de sus vecinos. Recuperado el 3 de noviembre de 2019, de http://www.rupestreweb.info/pictografiassachica.html

Londoño, E., Therrien, M., y Garzón, F. (2001). La divulgación de la arqueología en el Museo del Oro: promover la convivencia en Colombia. Boletín Museo del Oro (48), 66-79.

López, L. (2011). Topando piedras sumercé. Narraciones en torno a las piedras de Iza y Gámeza, Boyacá, Colombia, Recuperado el 4 de febrero de 2020, de http://www.rupestreweb.info/topandopiedras.html

López, L. (2018). Capítulo 7. Memorias rupestres. Prácticas culturales de la gente de montaña en los Andes. Arte rupestre en Colombia. Investigación, preservación, patrimonialización (págs. 179-196). Tunja, Colombia: UPTC.

López, L., Parra, D., Hernández, E., Martínez, L., Benavides, J., y Ramos, D. (2019). Didáctica, arqueología pública y educación patrimonial en el Parque Museo Arqueológico de Tunja - Uptc. O Ideário Patrimonial (13), 87-98. 
Marchante, A. (2016). Análisis macro y microespacial del abrigo inédito de Puerto Baterno (Aguso, Ciudad Real) y su inserción dentro del arte rupestre esquemático de los Montes de Ciudad Real, Valle de Alcudia y Sierra Madrona. Vínculos de Historia (5), 161-195.

Martínez, D. (2015). Lineamientos para la gestión patrimonial de sitios con arte rupestre en Colombia como insumo para su apropiación social, Bogotá, Colombia, Ministerio de Cultura de Colombia.

Menezes, L. (2010). Arqueología comunitaria, arqueología de contrato y educación patrimonial en Brasil. Jangwa Pana (9), 95-102.

Ministerio de Cultura. (2005). Manual para inventarios de bienes culturales muebles, Bogotá, Colombia, Ministerio de Cultura.

Montenegro, M. (2012). Arqueología en la escuela: experiencias en el sector septentrional del noroeste argentino. Chungara (44), 487-498.

Museo del Oro. Banco de la República. (2012). Museo del Oro: una mirada desde el patrimonio arqueológico, Bogotá, Colombia, Banco de la República.

Oliver, M.A. (1990). Kriging: A Method of Interpolation for Geographical Information Systems. International Journal of Geographic Information Systems (4), 313-332.

Pérez de Barradas, J. (1941). El arte rupestre en Colombia, Madrid, España, Instituto Bernardino de Sahagún.

Pérez, Pablo. (2013). Paisajes arqueológicos sagrados en territorio Lache - U'wa, Sierra Nevada de Güicán o Cocuy, Recuperado el 12 de marzo de 2020, de http://www.rupestreweb.info/paisajescocuy.html

Podgorny, I. (1994). Arqueología y Educación: La Inclusión de la Arqueología Pampeana en la Educación Argentina. [Tesis de doctorado] Universidad Nacional de La Plata, Buenos Aires

Pradilla, H. (2010). Pictografías, moyas y rocas del Farfacá, Tunja, Colombia, UPTC.

Simón, F. (1981 [1624]). Noticias Historiales de las conquistas de tierra firme en las indias occidentales. Tomo III, Bogotá, Colombia, Banco Popular.

Triana, M. (1972). La civilización chibcha. Cali, Colombia, Carvajal y compañía.

Trujillo, J. (2002). Las pinturas blancas de Pilar y Ceibita. Noticias de antropología y arqueología. Recuperado el 2 de febrero de 2020, de https://www.equiponaya.com.ar/congreso2002/ponencias/judith_trujillo.htm

Zabala, M. \& I. Roura. (2006). Reflexiones teóricas sobre patrimonio, educación y museos. Revista de Teoría y Didáctica de las Ciencias Sociales (11), 233-261. 